\title{
El espacio público y la infancia. Una reflexión sobre el diseño del espacio público y la formación integral en un contexto lúdico
}

Smara Gonçalves mdgoncalves@ubu.es

Escuela de Arte y Superior de Diseño de Burgos, Universidad de Burgos, España

Reference

Gonçalves, Smara; (2012) "El espacio público y la infancia. Una reflexión sobre el diseño del espacio público y la formación integral en un contexto lúdico", p. 46-50. In: Barbosa, Helena; Quental, Joana [Eds]. Proceedings of the 2nd International Conference of Art, Illustration and Visual Culture in Infant and Primary Education. São Paulo: Blucher, 2015. ISSN 2318-695X, ISBN: 978-989-98185-0-7

DOI 10.5151/edupro-aivcipe-10

Resumen

Palabras clave

Abstract

Keywords
En este artículo se analiza la importancia del juego en el desarrollo infantil y las posibilidades pedagógicas y sociales que puede presentar el espacio público si es diseñado para favorecer la actividad lúdica.

espacio público, juego, aprendizaje, memoria

This paper discusses the importance of play in child development and the educational and social opportunities that a public space may present if designed to encourage playful activity.

public space, play, learning, memory

\section{Introducción}

1 Enfoque pedagógico sobre el juego
Los primeros juegos, los espacios donde se desarrollaron, las relaciones que se establecieron son los recuerdos que significan los cimientos de la memoria vital de las personas y que configuran su identidad. Una memoria que es individual y colectiva cuando está enlazada a las vivencias del espacio público. El diseño del espacio público se debe entender como una actividad didáctica; cualquier interacción del ser humano con su entorno puede generar un contexto de aprendizaje: aprender a relacionarse de manera diversa con otras personas, a percibir de maneras que, cotidianamente, pasamos por alto,..., aprender nuevas formas de vivir. Por eso, cuando se crea un entorno para el ser humano, se están estableciendo posibilidades para el aprendizaje.

En la primera mitad del XIX, Friedrich Froebel (1782-1852) ya contempla la capacidad educativa del juego y argumenta la necesidad de disponer de espacios libres que permitan el juego colectivo, pero serán las aportaciones de Piaget (1896-1980), y Vygotski (1896-1934), un siglo más tarde las que desde el punto de vista psicológico profundicen en la investigación sobre el juego y el desarrollo del niño. Las teorías de Piaget (Martínez Criado, 1998) establecen cómo las distintas etapas evolutivas del niño condicionan su forma de jugar. Piaget diferencia cuatro estadios sobre el desarrollo intelectual. Cada uno de ellos tiene unas características intelectuales asociadas y presenta diferentes tipos de juego. El estadio sensoriomotor (O-2 años) se caracteriza porque la interacción con el medio se basa en la acción. En el estadio preoperacional (2-6 años) el niño utiliza nuevos recursos para relacionarse y puede comenzar a darse el juego simbólico.. Las capacidades deductivas están condicionadas por la apariencia perceptiva de los objetos con lo que inducen al error. El juego simbólico consiste en que el niño, en presencia de un determinado objeto, se representa un objeto ausente: un palo puede ser un 
2nd International Conference

Art, Illustration and Visual Culture in Infant and Primary Education $2^{\circ}$ Congreso Internacional

Aisual en Educación Infantil y Primaria
Congresso Internacional

de Arte, Ilustração e Cultura Visual

na Educação Infantil e Primária
Figuras 1 y 2. A la izquierda: Peter Brueghel el Viejo, Juego de niños (1560). Museo de Historia del Arte de Viena. A la derecha: Juguete experimental (2011). caballo o una piedra un coche. Se da "una diferenciación entre el significante y el significado". Para que el espacio público permita estimular este tipo de actividades tiene que disponer de elementos de carácter abstracto que favorezcan la interpretación simbólica. En el estadio operacional concreto (6-12 años) aparecen los juegos de reglas (carreras, canicas, etc.). Estos juegos ya no son individuales sino que precisan la relación coordinada entre distintos niños. Este tipo de juegos se han practicado tradicionalmente en el espacio público y han sido transmitidos de generación en generación (ver Figura 1). A partir de los 12 años, en el estadio operacional formal ya se pueden resolver problemas de gran complejidad y formulación abstracta mediante comprobaciones basadas en el razonamiento científico. A partir de esta etapa se pueden aplicar los juegos de construcción. Las teorías de Vygotsky (Martínez Criado, 1998) presentan el enfoque inverso asumiendo los planteamientos de Piaget: aunque el juego expresa capacidades ya consolidadas, lo más interesante es que el juego "facilita el paso de unas adquisiciones incipientes e inmaduras a otras afianzadas y permanentes". Vygotski no ve el juego simplemente como un rasgo que acompaña a las distintas etapas evolutivas del niño, sino que considera que es un condicionante del desarrollo "puesto que el niño avanza mediante la actividad lúdica". Además este desarrollo está condicionado por el contexto cultural y social, y mediante el juego los niños aprenden a integrarse en la sociedad.

El elemento que caracteriza una actividad como juego es la actitud del jugador: "el componente de libertad de elección es inseparable del mundo del juego. Es imposible obligar a jugar. Y esta libertad de elección, seguimiento y acción es esencial e inseparable del mundo de los sentimientos" (Martínez Criado, 1998). Pero ¿la libertad de elección puede estar condicionada por unas instrucciones previas, por un modo de empleo prefijado, o dicho de otro modo ¿la instrucción condiciona la libre experimentación? Elementos con una vocación plástica e indefinida y juegos infantiles normalizados destinados a una utilización específica, ¿tienen el mismo efecto en el desarrollo formativo que el juego aporta al niño?
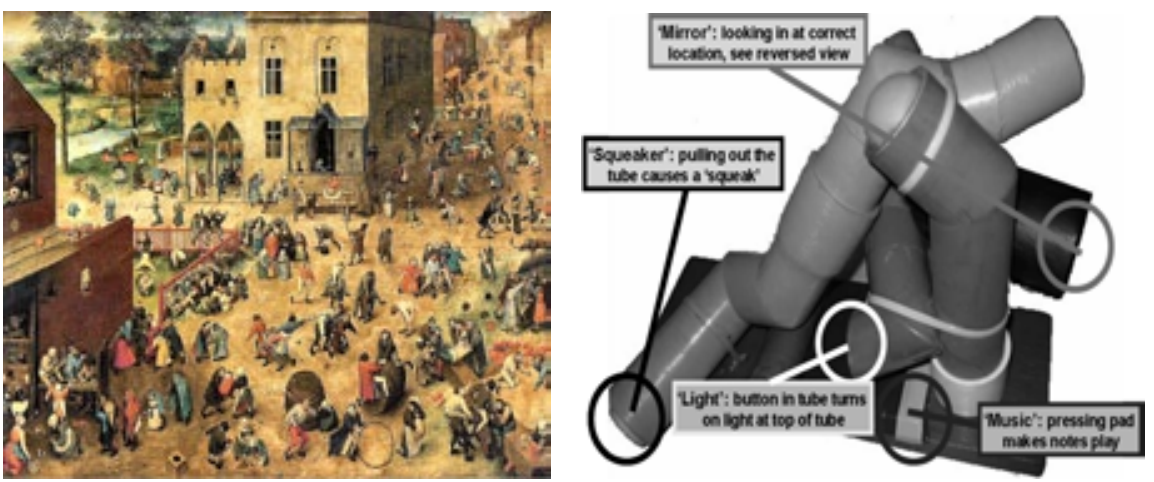

Elizabeth Bonawitz y Patrick Shafto (Bonawitz et al., 2011) estudian el aprendizaje de los niños entre cuatro y seis años comparando las situaciones de instrucción previa con aquellas en las que se desarrolla el aprendizaje por descubrimiento. Se diseñó un juguete complejo que no evidenciaba sus funcionalidades ni forma de uso (Figura 2). El juguete tiene tubos móviles, botones y resortes ocultos que permiten conseguir cuatro efectos: obtener un pitido, encender una luz, hacer sonar notas musicales y definir una posición de espejos ocultos en los tubos que devuelve una imagen invertida del que mira. En el experimento se trabajó con diferentes grupos de niños. A un primer grupo se le dijo cómo funcionaba el juguete y se le explicó sólo una de las funciones. Dos grupos de niños tuvieron sólo información parcial del funcionamiento de esa función. Un cuarto grupo no tuvo ningún tipo de información. Los resultados aportaron varias informaciones. Un primer aspecto está relacionado con el tiempo que los niños dedicaron a jugar con el objeto. El grupo con la instrucción previa completa fue el que menos tiempo dedicó al juguete y el grupo sin ningún tipo de información anterior fue el que más tiempo dedicó a experimentar. Un segundo aspecto analizado tiene que ver con el grado de conocimiento alcanzado por los distintos grupos de niños. El grupo con formación previa dedicó la mayor parte de su tiempo a reproducir las acciones del mecanismo que se les había enseñado y fue el que menos funciones nuevas descubrió. Por el contrario, los niños de los grupos con menos o nula instrucción dedicaron más tiempo a experimentar con las posibilidades del juguete y descubrieron más funciones. 
2nd International Conference Art, Illustration and Visual Culture in Infant and Primary Education $2^{\circ}$ Congreso Internacional

Arte, llustración y Cultura Visual en Educación Infantil y Primaria de Arte, llustração e Cultura Visual

na Educação Infantil e Primária

De esta investigación se deduce que la instrucción previa proporciona un aprendizaje más eficiente, pero lo hace a costa de limitar los deseos de exploración y, por tanto, disminuyendo las posibilidades de disfrute al descubrir información nueva. Los investigadores concluyen que, para la adecuada formación del niño, es necesario alcanzar el difícil equilibrio entre la enseñanza directa, que da información sobre lo que otras generaciones han hecho, y el aprendizaje por descubrimiento, que desarrolla la capacidad de hacer cosas nuevas. En este punto volvemos a retomar el asunto que nos ocupa: las posibilidades lúdicas del niño en el espacio público. Descampados, palos, piedras,..., objetos y elementos sin una función y sin un modo de empleo preestablecido que eran el contexto habitual del juego en el espacio público de generaciones anteriores, se han ido sustituyendo por mobiliario infantil de catálogo que establece de forma evidente su forma de utilización, incluso el rango de edades para el que es adecuado. De esta forma el espacio público pasa de ser un lugar para la experimentación a un entorno regido por una fuerte normatividad. Las investigaciones respaldan la necesidad de un espacio público que aporte posibilidades de experimentación. Por otro lado, si atendemos a las cualidades de identidad de un espacio, no parece adecuada la solución de estandarizar las zonas de juego porque acaba configurando zonas residuales e indiferenciables en las distintas ciudades. Por último debemos revalorizar las posibilidades plásticas que suponen la creación de elementos, zonas, objetos, con un grado de abstracción e indefinición, que no permitan ser clasificados de forma evidente como elementos de mobiliario urbano o esculturas, y, por lo tanto, lo que demanden sea la experimentación, vivir el espacio.

\section{El espacio público actual: carencias y objetivos}

En la Figura 3 vemos fotogramas de un documental de 1947 rodado en Inglaterra donde los niños reproducen batallas de la Segunda Guerra Mundial. Vemos en las imágenes cómo los niños adaptan el desarrollo de su juego a las posibilidades que les brinda el espacio: pequeños y grandes desniveles, charcos generados en los restos de una construcción,... El espacio, al ser flexible e indiferenciado, es susceptible de adaptarse a las necesidades lúdicas de los niños.

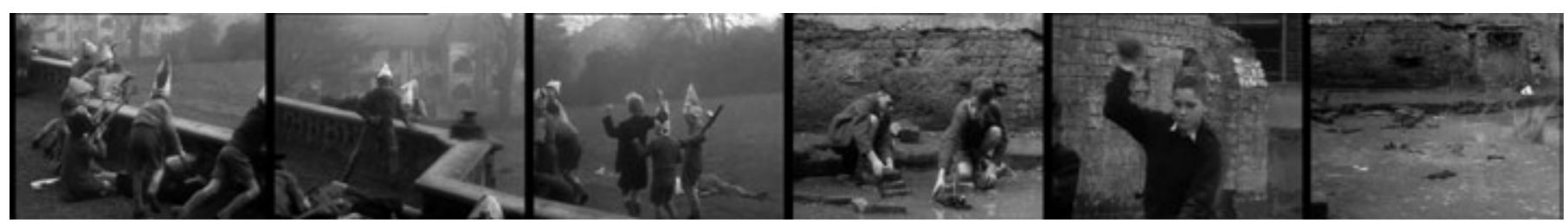

Figura 3. Niños jugando a la guerra en Inglaterra en 1947. Fotogramas extraídos de la película Children Learning by Experience (Battle scenes). Documental. British Library, 1947. British Film Institute.
Podríamos generalizar diciendo -y siendo conscientes de las diferencias entre el contexto rural y urbano, las diferentes situaciones de países, etc.- que los juegos tradicionales de los niños en el espacio público se mantuvieron hasta mediados del siglo XX. A partir de ese momento el juego en el espacio público no es protagonista.

Después de las experiencias del Movimiento Moderno en el espacio público, se empezó a pensar críticamente en nuevos planteamientos de intervención. Gillo Dorfles (Dorfles, 1973) ya hablaba "de la necesidad de una memorización afectiva que devuelva al habitante individual la conciencia de pertenecer a un territorio determinado". Establece unos factores fundamentales para entender la relación del hombre con su entorno: 1) la memorización afectiva del ambiente y del territorio urbano por parte del habitante, y la importancia de la formación de un microambiente (o sea, de un ambiente circunscrito, dentro del cual se puede realizar esa "memorización afectiva" que persigue "la posibilidad de dejar grabados en la propia memoria algunos elementos, no sólo visuales, sino también acústicos, olfativos, táctiles, [...] capaces de hacer volver a la memoria el aspecto de un ambiente determinado"); 2) las relaciones intersubjetivas entre los habitantes; 3 ) la posibilidad de un reconocimiento específico del ambiente a partir de algunos rasgos distintivos esenciales; 4) la necesidad de crear nuevos elementos simbólicos en sustitución de los antiguos o ausentes, fácilmente reconocibles por los habitantes. Cree que toda actividad del diseñador ambiental debe estar guiada por elementos de carácter ético. Con este planteamiento se opone a las preferencias funcionalistas y técnicas, y en definitiva pretende que los objetivos de cualquier intervención en el ambiente se centren en "desarrollar en el hombre" la tendencias éticas y estéticas. 
$2^{\text {nd }}$ International Conference Art, Illustration and Visual Culture in Infant and Primary Education $2^{\circ}$ Congreso Internaciona

Arte, llustración y Cultura Visual en Educación Infantil y Primaria $2^{\circ}$ Congresso Internacional

de Arte, Ilustração e Cultura Visual

na Educação Infantil e Primária

\section{Propuestas destacadas}

Figuras 4, 5 y 6. A la izquierda: Noguchi, I., Contoured Playground (1941). Bronce. $7 \times 66.7 \times 66.7 \mathrm{~cm}$. En el centro: Aldo van Eyck's, Playgrounds Bertelmanplein, 1955. A la derecha: David Rockwell, Imagination Playground (2010)
Muntañola (Muntañola i Thornberg, 1980) reconoce en la deprivación un tipo de muerte del medio ambiente, considerado como el elemento que posibilita la relación, el entorno donde se desarrolla la cultura. Consiste en "la progresiva simplificación del medio ambiente reduciendo su riqueza perceptiva, kinestésica, etc., hasta llegar a construir medios artificiales en los que el cuerpo no pone en juego apenas sus sentidos, y en los que no hay diferencias cuando de un lugar a otro lugar". Esta situación "convierte [al medio ambiente] en un medio simplificado, que llega a ser invivible al anular las posibilidades psicológicas y sociológicas de los cuerpos humanos". Muntañola explica cómo muchos diseños modernos buscando reducir costes "en lugar de pensar formas baratas de solucionar las necesidades, simplifican las necesidades, o sea el problema al cual tenían que responder. En lugar de buscar una solución cambian el problema por otro más simple".

Frente a esta degradación de la calidad del espacio público, en los últimos años, la ciudad contemporánea ha sido objeto de interés de la actividad artística que la ha utilizado como campo de experimentación y reflexión.

Isamu Noguchi comenzó a proponer en los años 30 esculturas a gran escala que consistían en manipular el terreno para generar espacios de juego (Larrivee, 2011). Estas obras no llegaron a ser construidas: fueron incomprendidas seguramente por ser demasiado novedosas. Lo que estaba proponiendo eran grandes manipulaciones del terreno unos 30 años antes de que apareciera el land art. Además en ese momento resultaba una propuesta sin precedentes proponer una escultura de desmesurada dimensión que tenía como objetivo el entretenimiento de los niños. Un entretenimiento que se estimulaba simplemente con las manipulaciones del terreno favoreciendo las carreras, los saltos y los deslizamientos. Esto también era una idea muy nueva que calará mucho más tarde, en los años 6o, con el desarrollo del concepto de los adventure playgounds.

Después de la Segunda Guerra Mundial Aldo van Eyck realizó múltiples intervenciones en solares de Amsterdam convirtiéndolos en espacios de juegos para niños. Con austeridad económica supo crear espacios de juego que favorecían el uso con libertad. Siempre antepuso las necesidades lúdicas a conceptos formales o compositivos.

Más cercano en el tiempo es el Imagination Playground de David Rockwell, creado en el año 2010. Consiste en un conjunto de piezas de espuma de grandes dimensiones que permiten al niño remodelar la configuración de su entorno de juego. De esta manera se favorece el juego libre, no estructurado. Su planteamiento da continuidad a los juegos tradicionales de construcción, cuya importancia pedagógica fue evidenciada por Froebel, aumentándolos de escala, de manera que permiten satisfacer la tendencia natural del niño a construir, a la vez que redefine su espacio vital. No obstante, aunque estos bloques tienen un tamaño mucho mayor al usual, no pueden estar permanentemente en el espacio público sin vigilancia, por lo que no deben dejar de considerarse como un juguete de grandes dimensiones y no como mobiliario urbano o instalación permanente. Esto condiciona la actividad de los niños a la presencia continuada de algún adulto.
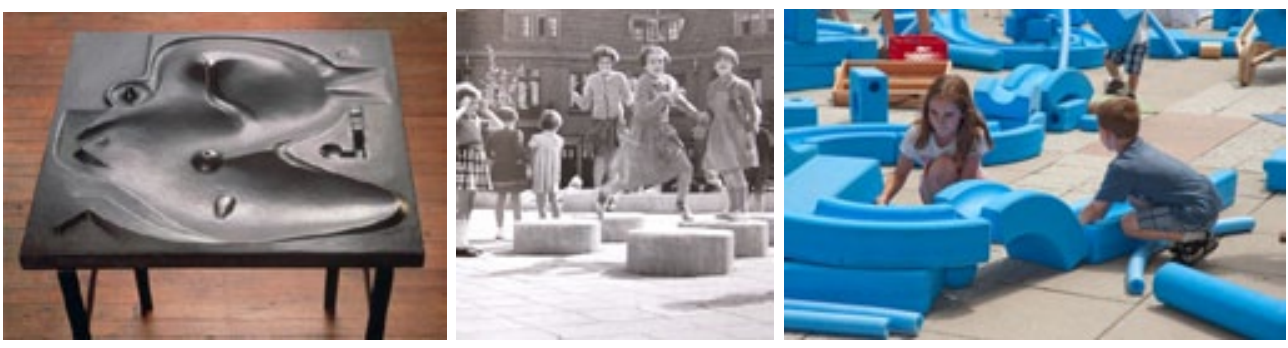

En el ámbito de las instalaciones artísticas permanentes se destaca la Crown Fountain de Jaume Plensa. Plensa crea un entorno de carácter cívico, presidido por los rostros de ciudadanos anónimos de Chicago y recupera un elemento básico de la vida, el agua, con una propuesta lúdica. Los niños juegan entre sí e interactúan con el entorno, viviendo experiencias excitantes que formarán parte de su memoria vital y reforzarán su vinculación afectiva con el lugar. 
2nd International Conference Art, Illustration and Visual Culture in Infant and Primary Education $2^{\circ}$ Congreso Internacional

Arte, llustración y Cultura Visual en Educación Infantil y Primaria
Congresso Internacional

de Arte, llustracão e Cultura Visual

na Educação Infantil e Primária
Figuras 7, 8 y 9. A la izquierda: Jaume Plensa, Millennium Park, Crown Fountain(2004). Foto de Vincent (2010). En el centro y derecha: Romi Khosla Design Studio, Children's Playground (2004). Harayana.

\section{Conclusión}

\section{Referencias bibliográficas}

Anón (1955). Bertelmanplein-kl-1955-287×300.jpg. [Consult.13 mayo 2012]. Disponible en: <http://www. visual-art-research.com/wp-content/uploads/2010/04/Bertelmanplein-kl-1955-287×300.jpg>

Anón (1947). Children Learning by Experience (Battle scenes). [Online Video]. [Consult.29 julio 2011]. Disponible en: <http://www.bl.uk/learning/langlit/playground/browseadultview.html\#cm=Videos\&g $\mathrm{m}=$ Pretend\&id=120551\&id2=120908>.

Anón (s. f.). Welcome to Imagination Playground: Videos \& Photos. [Online]. [Consult.13 mayo 2012]. Disponible en: <http://www.imaginationplayground.com/photos/>.

Bonawitz, E., Shafto, P., Gweon, H., Goodman, N.D., Spelke, E. \& Schulz, L. (2011). The double-edged sword of pedagogy: Instruction limits spontaneous exploration and discovery. Cognition. [Online]. 120 (3). p. 322-330. [Consult.31 julio 2011]. Disponible en: <http://www.scie

ncedirect.com/science/article/pii/So010027710002258>.

Brueghel (1560). Juego de niños. [Online]. [Consult.13 mayo 2012]. Disponible en: <http://www. gamesmuseum.uwaterloo.ca/VirtualExhibits/Brueghel/children.jpg>.

Dorfles, G. (1973). Dal significato alle scelte. Traducido por Carlos Manzano. $1^{\text {a }}$ Ed. Barcelona: Editorial Lumen, S.A (1975).

Larrivee, S.D. (2011). Playscapes: Isamu Noguchi's Designs for Play. Public Art Dialogue. [Online]. 1 (1). p. 53-80. [Consult.27 julio 2011]. Disponible en: <http://www.tandfonline.com/doi/full/10.1080/2150 2552.2011.536711>.

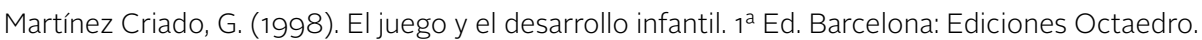

Muntañola i Thornberg, J. (1980). Didáctica medioambiental : fundamentos y posibilidades. $1^{\text {a }}$ Ed. Barcelona: Oikos-Tau, S.A. Ediciones.

Noguchi, I. (1941). Contoured Playground. [Online]. [Consult.13 mayo 2012]. Disponible en: <http://www. noguchi.org/museum/collection/contoured-playground>.

Romi Khosla Design Studio (2004). Children's Playground. Harayana. [Online]. [Consult.13 mayo 2012]. Disponible en: <http://www.rk-ds.com/index-3-5.html>.

Vincent (2010). Chicago (ILL) Millennium Park, Crown Fountain, Jaume Plensa. 2004. [Online]. [Consult.13 mayo 2012]. Disponible en: <http://www.flickr.com/photos/endymion120/482463586o/>. 